\title{
Effects of Inexpressive Aggression on Depression in College Students: Cross Cultural Study between Japan and Russia
}

\section{Takeyasu Kawabata1, Ken-ichi Ohbuchi², Svetlana Gurieva ${ }^{3}$, Victoria Dmitrieva4, Olga Mikhalyuk ${ }^{3}$, Veronika Odintsova ${ }^{5}$}

${ }^{1}$ Department of Human Psychology, Shokei Gakuin University, Natori, Japan

${ }^{2}$ Open University of Japan, Sendai, Japan

${ }^{3}$ Department of the Social Psychology, St. Petersburg State University, St. Petersburg, Russia

${ }^{4}$ Department of Ontopsychology, St. Petersburg State University, St. Petersburg, Russia

${ }^{5}$ Department of Psychology, St. Petersburg State University, St. Petersburg, Russia

Email:kawabata@shokei.ac.jp

How to cite this paper: Kawabata, T., Ohbuchi, K., Gurieva, S., Dmitrieva, V., Mikhalyuk, O., \& Odintsova, V. (2016). Effects of Inexpressive Aggression on Depression in College Students: Cross Cultural Study between Japan and Russia. Psychology, 7, 1575-1586.

http://dx.doi.org/10.4236/psych.2016.713152

Received: September 26, 2016

Accepted: November 11, 2016

Published: November 14, 2016

Copyright $\odot 2016$ by authors and Scientific Research Publishing Inc. This work is licensed under the Creative Commons Attribution International License (CC BY 4.0). http://creativecommons.org/licenses/by/4.0/

\begin{abstract}
The aim of this study is to examine the cross-cultural effects of inexpressive aggression on depression in terms of emotion regulation in Japanese and Russian students. Two hundreds and six Japanese students and 243 Russian students read scenarios depicting socially provocative situations, and asked to rate their own anger, the other party's hostile intent and happy emotion, and the extent in which they would use emotion regulations (distraction, suppress, and reappraisal), and finally their own other kinds of negative emotions (melancholy, anxiety, and depression) on a 9-point rating scale. The results showed that 1 ) Russians more frequently used suppression as emotion regulation than Japanese did, and suppression of anger decreased depressive emotions among Russians but not among Japanese. 2) Japanese would more frequently use reappraisal than Russians and reappraisal would increase depressive emotions among Japanese but not among Russians. 3) Distraction increased depressive emotions both among Japanese and Russian participants. 4) Females used more emotion regulation and felt more depressive emotions than males in both samples.
\end{abstract}

\section{Keywords}

Social Information Processing, Inexpressive Aggression, Emotion Regulation, Anger, Depression

\section{Introduction}

One may act aggressively as coping with an interpersonal friction. Aggressive behavior 
takes a variety of forms from starting a bad rumor, indirective and well-considered way, to using impulsive violence in a fit of rage. Aggression has been defined as a behavior that is intended to hurt or harm other (Crick \& Grotpeter, 1995). Researchers distinguish two types of aggression, reactive and proactive, based on overt forms and assumed generating mechanisms, on which are especially focused in social information processing model (Crick \& Dodge, 1996; Dodge \& Coie, 1987). Reactive aggression is a kind of behavior expressing anger as a reaction to a perceived threat or frustration, with an aim to defense oneself by hurting or harming a person who is seen as a source of threat or frustration. On the one hand, proactive aggression is a behavior conducted instrumentally to achieve a goal or to remove some negative situations, not necessarily associated with anger (Dodge \& Coie, 1987). Yamasaki and Nishida (2009) suggested a more elaborate classification: they divided reactive aggression into reactive-expressive (overt verbal or physical aggression) and reactive-inexpressive (covert hostility), and proposed to treat relational aggression, which is a subtype of proactive aggression, as a different category.

Reactive-inexpressive aggression, which generates hostility, is shown to elicit depression. It is demonstrated that hostility negatively correlates with social support and by way of weakening social support, hostility increases depression (Bridewell \& Chang, 1997), and especially in females, to suppress the expression of anger enhances depression (Brummett, Babyak, Barefoot, Bosworth, Clapp-Channing, Siegler, Williams, \& Mark, 1998).

To suppress anger has been regarded as a positive mental mechanism. It is called emotion regulation that promotes interpersonal functioning, personal well-being (Gross \& John, 2003), and intimacy in close relationship (Field, 1994), and cross-cultural research has found that immigrants and sojourners with better emotion regulation have less depression, anxiety, culture shock, and homesickness and report higher levels of happiness, well-being, marital satisfaction, language proficiency, and income (Matsumoto, LeRoux, Bernhard, \& Gray, 2004; Matsumoto et al., 2003; Matsumoto et al., 2001).

But some researchers have raised a question about this view of emotion regulation. In a study in which male Japanese students were asked to rate their anger and aggression after reading scenarios depicting interpersonal conflicting situations, Kawabata and Ohbuchi (2014) found that anger and emotion regulation increased depression. The results suggest that even in males, suppression of anger increases depression and, contrary to a common belief, emotion regulation might cause negative inner states.

In the light of the fact that there are different strategies of emotion regulation, Matsumoto, Yoo, and Nakagawa (2008) studied cultural differences focusing on reappraisal (reinterpretation of an emotion-eliciting situation to change its emotional impact) and suppression (inhibition of an ongoing emotional expressive behavior). They demonstrated based on the studies of 23 countries that in collectivistic cultures, suppression is dominant and it positively correlates with reappraisal, whereas in individualistic ones, reappraisal is dominant and it negatively correlates with suppression. Therefore, crosscultural research is needed to study the relationship between emotion regulation and 
depression.

Both Japan and Russia were high suicide rates countries (WHO, 2012). And it was estimated that as many as $90 \%$ of individuals who have died by suicide had a mental disorder, $60 \%$ of which were depressed at the time (WHO, 2006). So, Japan and Russia are assumed to have a high number of depressive people. Cross-cultural studies between these countries may provide an insight into the psychological mechanisms by which the inhibition of anger generates depression and cultural factors determining the mechanisms. The purpose of this study is to explore the relationships of anger and emotion regulation (suppression, distraction, and reappraisal) with depression, and to reveal gender differences and cultural effects by comparing the previously published Japanese data (Kawabata \& Ohbuchi, 2014) with newly collected Russian data.

Based on the studies in US, Japan, South Korea, and Russia, Matsumoto, Takeuchi, Andayani, Kouznetsova, and Krupp (1998) reported that Japan is the least collectivistic country, whereas in Russia as a collectivistic country and people tend to exert more control over emotional displays and put more importance on the maintenance of harmony and cohesion. Triandis, Bontempo, Villareal, Asai and Lucca (1988) reported that Japanese tend to express negative emotions against out-groups, but to suppress it in in-group contexts. Those results indicated that emotion regulation and emotion expression of Japanese might be different between in out-group and in-group. In this study, therefore, we expected that Russians will exert more suppression as emotion regulation than Japanese (Hypothesis 1) and suppression will be associated with depression in Russians (Hypothesis 2), while Japanese will exert more reappraisal than Russians (Hypothesis 3) and reappraisal will be associated with depression in Japanese (Hypothesis 4).

Compared with males, females tend to become depressive (Culbertson, 1997; Weissman et al., 1996), to suppress anger (Gross \& John, 2003), and to exert maladaptive emotion regulations (Garnefski et al., 2004). Based on these research findings, we predicted that females will be more likely to exert emotion regulations and to become depressive than males (Hypothesis 5).

\section{Method}

\subsection{Participants}

Two hundreds and six students of a Japanese university (94 males, 112 females; $M$ age = $18.7 \pm 0.9$ ) and 243 students of a Russian university (102 males, 147 females; $M$ age $=$ $20.29 \pm 1.3$ ) participated in the study.

\subsection{Procedures}

Participants joined this study in classrooms. They read three scenarios depicting situations provoking reactive aggression which were used in Aizawa (2011). The Japanese version (Aizawa, 2011) was translated into the Russian one through proofreading by a native Russian speaker. Participants were asked to rate their own anger, and other party's hostile intent and happy emotion, the extent in which they would use emotion regulations (distraction, suppress, and reappraisal), and finally their own other kinds of 
negative emotions (melancholy, anxiety, and depression) on a 9-point rating scale.

\subsection{Measures}

The scenarios depicted three interpersonal conflict situations ("A person bumped into your shoulder when you were walking a road, and the person walked away without saying anything," "A person turned off lights when you read a book in a classroom," and "A taxi had passed by ignoring your signal."). Participants were instructed to imagine that they were actually experiencing the episodes. After reading each scenario, participants rated the following cognitive and emotional variables on a scale ranging from 1 "Not at all" to 9 "Definitely."

Hostile intent attribution to the provoking person. After each scenario, participants were asked to rate the extent to which they perceived the person intentionally bumped into them (turned off lights or ignored their signal).

Perception of pleasure of the provoking person. Participants were asked to rate how strongly they perceived the person felt pleasure.

Own anger. Participants were asked to rate how strongly they would feel anger if they were a victim.

Emotional regulation. By modifying items used in de Castro, Merk, Koops, Veerman and Bosch (2005), we construed items to measure three adaptive modes of emotional regulation (distraction, suppression, and reappraisal). Participants were asked whether they would do something to make them feel better: distraction ("talk it with someone" and "do something fun"), suppression ("avoid to think about it" and "forget it"), reappraisal ("it was an accident" and "I had a bad luck").

Aggression. Participants were asked to rate whether they would do two aggressive behaviors (aggression 1 "chasing the person to make him to apologize" and aggression 2 "catch the person's shoulder to turn him around").

Depressive emotions. Participants were asked to rate their feelings (melancholy, anxiety, and depression).

\subsection{Consideration of Human Rights}

In this study, human rights of participants were considered as follows. The following statements were printed clearly on the face sheet of the questionnaire: "there is no right or wrong answer," "if you do not want to answer some questions, please skip these," "because survey answers are analyzed statistically, each personal answer is not identified," and "the author disposes of all questionnaires responsibility".

\section{Results}

\subsection{Statistical Analysis}

As preliminary analysis, we computed descriptive statistics and correlation analysis. Next, we conducted $t$-test to examine cultural differences. Then, hierarchical regression analysis was performed to test research hypotheses separately in each country sample. The follow-up analyses for Japanese sample were conducted in the way that Aiken and 
West (1991) recommended.

\subsection{Correlations between the Variables}

Scores of each variable were averaged over the three scenarios. Descriptive statics of these variables are shown in Table 1. And correlations between them are presented in Table 2. Among females, the tendency to use emotion regulation was positively correlated with negative emotions.

Because aggressive behavior 1 and 2 significantly positively correlated with each other and the correlations between three negative emotions (melancholy, anxiety, and depression) were significant, they were combined for (aggressive behavior and depressive emotion).

Table 1. Means and SDs of all the measures $(n=455)$.

\begin{tabular}{ccc}
\hline & Average & SD \\
\hline Age & 19.55 & 1.39 \\
Hostile Attribution & 4.54 & 1.69 \\
Happy Attribution & 3.15 & 1.66 \\
Own Anger & 5.92 & 1.76 \\
Distraction & 5.45 & 1.73 \\
Aggressive Intent 1 & 2.64 & 1.69 \\
Aggressive Intent 2 & 2.02 & 1.38 \\
Suppress & 5.86 & 1.65 \\
Reappraisal & 5.05 & 1.68 \\
Melancholy & 3.82 & 2.40 \\
Anxiety & 3.52 & 1.97 \\
Depression copy & 4.55 & 2.01 \\
\hline
\end{tabular}

Table 2. Zero-order correlations of variables.

\begin{tabular}{|c|c|c|c|c|c|c|c|c|c|c|c|}
\hline & 1 & 2 & 3 & 4 & 5 & 6 & 7 & 8 & 9 & 10 & 11 \\
\hline 2 Hostile attribution & $-.238^{\star *}$ & & & & & & & & & & \\
\hline 3 Happy attribution & -.078 & $.335^{\star *}$ & & & & & & & & & \\
\hline 4 Own anger & -.078 & $.345^{\star *}$ & .015 & & & & & & & & \\
\hline 5 Aggression 1 & $-.276^{\star *}$ & $.335^{\star *}$ & .094 & $.386^{* *}$ & & & & & & & \\
\hline 7 Distraction & $.176^{\star *}$ & .060 & -.127 & $.425^{\star *}$ & $.216^{* *}$ & .077 & & & & & \\
\hline 8 Suppress & .049 & $-.159^{\star *}$ & -.059 & -.083 & $-.199^{\star *}$ & $-.211^{\star *}$ & .036 & & & & \\
\hline 9 Reappraisal & $.226^{* *}$ & $-.250^{\star *}$ & -.221 & .008 & $-.200^{\star *}$ & $-.209^{\star *}$ & $.298^{\star *}$ & $.311^{* *}$ & & & \\
\hline 10 Melancholy & $.108^{*}$ & $.207^{\star *}$ & -.122 & $.472^{* *}$ & $.161^{\star *}$ & .032 & $.417^{* *}$ & $-.115^{*}$ & $.278^{* *}$ & & \\
\hline
\end{tabular}

Note: ${ }^{*} p<.01,{ }^{*} p<.05$. 


\subsection{Cultural Differences}

To examine cultural differences, we conducted $t$-test for each variable between Japanese and Russian samples. As shown in Table 3, Japanese participants were significantly higher than Russian ones in the perception of other party's hostility, own anger, reappraisal of emotion regulation, and three depressive emotions (melancholy, anxiety, and depression). Russian participants were significantly higher than Japanese ones in age, the perception of other party's pleasure, and suppression of emotion.

Because of these cultural differences, we conducted hierarchical regression analysis of depressive emotion separately in each country sample.

\subsection{Hierarchical Regression Analysis}

To test the research hypotheses, we performed a hierarchical regression analysis for each country, in which depressive emotions were a dependent variable and others were independent variables. Independent variables, which were centered to avoid nonessential multicollinearity, were entered in four steps. In Step 1, participants' age and gender were entered. The entry of variables in the other steps was determined based on the revised social information processing model (de Castro et al., 2005; Kawabata \& Ohbuchi, 2014): that is, Step 2 included social informational variables (hostile attribution, happy attribution, and own anger) and in Step 3, three emotion regulation variables (reappraisal, suppression an distraction) and aggressive behavior were added. In Step 4, further, interactions of gender ( male $=0$ and female $=1$ ) and other independent variables were entered in order to test gender differences in the effects of other independent variables.

Variance inflation factors (VIFs) of the independent variables ranged from 1.0

Table 3. Nationality differences in all the measures.

\begin{tabular}{|c|c|c|c|c|c|c|c|}
\hline & \multicolumn{2}{|c|}{ Average } & \multicolumn{2}{|c|}{ SD } & $\mathrm{d}$ & $\mathrm{t}$ & \\
\hline Age & 18.67 & 20.29 & 0.89 & 1.30 & 439.29 & 15.67 & ** \\
\hline $\operatorname{Sex}(0=M, 1=F)$ & 0.54 & 0.59 & 0.50 & 0.49 & 453.00 & 1.00 & \\
\hline Hostile Attribution & 4.75 & 4.36 & 1.50 & 1.82 & 452.97 & -2.52 & * \\
\hline Own Anger & 6.70 & 5.26 & 1.49 & 1.70 & 451.49 & -9.64 & $* *$ \\
\hline Distraction & 6.16 & 4.86 & 1.59 & 1.61 & 453.00 & -8.62 & ** \\
\hline Aggressive Intent & 2.45 & 2.23 & 1.66 & 1.17 & 356.94 & -1.61 & \\
\hline Suppress & 5.62 & 6.07 & 1.72 & 1.57 & 453.00 & 2.95 & ** \\
\hline Depression & 4.71 & 4.42 & 2.07 & 1.95 & 453.00 & -1.53 & \\
\hline
\end{tabular}

Note: ${ }^{* *} p<.01,{ }^{\star} p<.05$. 
through 1.7 in the Russian sample and 1.0 through 1.5 in the Japanese sample, indicating that multicollinearity of the independent variables did not substantially bias the results.

Table 4 and Table 5 reports the standardized partial regression coefficients (betas) and changes in R-squares of Russian and Japanese. The results from the final model showed that even after the variance associated with the covariates was accounted for, gender, perception of other party's happy attribution, own anger, distraction, suppression were unique predictors of depression in the Russian sample. Females or participants who more attributed happiness to other party, felt more anger, and used more distraction of emotion regulation were more likely to be depressive, whereas those who used more suppression were more likely to be less depressive.

In the Japanese sample, females or participants who felt more anger and used more distraction and reappraisal of emotion regulation were likely to be depressive. Because only the gender $\times$ own anger interaction in the Japanese sample was significant, follow-up analyses were conducted in the way that Aiken and West (1991) recommended. Regression analyses were conducted separately for the following four groups: males high (1 SD above the mean of males) in own anger, males low (1SD below the mean), females high (1 SD above the mean of females) and females low. The results were shown in Figure 1. Although own anger was not significantly related to depression for

Table 4. Standardized Beta coefficients and change in r-squares for the associations between attribution, anger and emotion regulation in Russian students $(n=249)$.

\begin{tabular}{|c|c|c|c|c|c|c|c|c|}
\hline & \multicolumn{8}{|c|}{ Standardized Beta } \\
\hline & \multicolumn{2}{|c|}{ Step 1} & \multicolumn{2}{|c|}{ Step 2} & \multicolumn{2}{|c|}{ Step 3} & \multicolumn{2}{|c|}{ Step 4} \\
\hline & Beta & $\Delta \mathrm{R}^{2}$ & Beta & $\Delta \mathrm{R}^{2}$ & Beta & $\Delta \mathrm{R}^{2}$ & Beta & $\Delta \mathrm{R}^{2}$ \\
\hline Age & .07 & .02 & .10 & $.31^{\star *}$ & .08 & $.40^{* *}$ & .08 & .01 \\
\hline Gendera & $.13^{\star}$ & & $.21^{\star *}$ & & $.12^{*}$ & & $.13^{*}$ & \\
\hline Hostile attribution & & & .03 & & .04 & & .05 & \\
\hline Happy attribution & & & $.28^{* *}$ & & $.25^{\star *}$ & & $.27^{\star *}$ & \\
\hline Own anger & & & $.39^{* *}$ & & $.34^{* *}$ & & $.33^{* *}$ & \\
\hline Distraction & & & & & $.17^{* *}$ & & $.17^{\star *}$ & \\
\hline Aggressive intent & & & & & -.05 & & -.04 & \\
\hline Suppress & & & & & $-.17^{\star \star}$ & & $-.16^{\star *}$ & \\
\hline Reappraisal & & & & & .09 & & .10 & \\
\hline Sex $\times$ Hostile attribution & & & & & & & -.03 & \\
\hline Sex $\times$ Happy attribution & & & & & & & .06 & \\
\hline Sex $\times$ Own anger & & & & & & & .05 & \\
\hline Sex $\times$ Distraction & & & & & & & .04 & \\
\hline Sex $\times$ Aggressive intent & & & & & & & -.02 & \\
\hline Sex $\times$ Suppress & & & & & & & -.03 & \\
\hline Sex $\times$ Sreappraisal & & & & & & & -.05 & \\
\hline
\end{tabular}

Note: Gender code $0=$ male $/ 1=$ female; ${ }^{\star} p<.05 .{ }^{* *} p<0.1$. 
Table 5. Standardized beta coefficients and change in $r$-squares for the associations between attribution, anger and emotion regulation in japanese students $(\mathrm{n}=206)$.

\begin{tabular}{|c|c|c|c|c|c|c|c|c|}
\hline & \multicolumn{8}{|c|}{ Standardized Beta } \\
\hline & \multicolumn{2}{|c|}{ Step 1} & \multicolumn{2}{|c|}{ Step 2} & \multicolumn{2}{|c|}{ Step 3} & \multicolumn{2}{|c|}{ Step 4} \\
\hline & Beta & $\Delta \mathrm{R}^{2}$ & Beta & $\Delta \mathrm{R}^{2}$ & Beta & $\Delta \mathrm{R}^{2}$ & Beta & $\Delta \mathrm{R}^{2}$ \\
\hline Age & .00 & $.04^{*}$ & -.03 & $.05^{*}$ & -.03 & $.10^{\star *}$ & -.04 & $.07^{\star}$ \\
\hline Gendera & $.21^{*}$ & & $.22^{* *}$ & & $.16^{*}$ & & $.04^{\star}$ & \\
\hline Hostile attribution & & & .08 & & $.17^{*}$ & & $.16^{*}$ & \\
\hline Happy attribution & & & .08 & & .08 & & $.11^{*}$ & \\
\hline Own anger & & & $.17^{\star}$ & & $.17^{*}$ & & $.22^{\star *}$ & \\
\hline Distraction & & & & & .13 & & $.10^{* *}$ & \\
\hline Aggressive intent & & & & & .02 & & -.02 & \\
\hline Suppress & & & & & -.07 & & -.07 & \\
\hline Reappraisal & & & & & $.32^{* *}$ & & $.32^{\star *}$ & \\
\hline Sex $\times$ Hostile attribution & & & & & & & .05 & \\
\hline Sex $\times$ Happy attribution & & & & & & & .16 & \\
\hline Sex $\times$ Own anger & & & & & & & $.39^{\star *}$ & \\
\hline Sex $\times$ Distraction & & & & & & & -.14 & \\
\hline Sex $\times$ Aggressive intent & & & & & & & -.14 & \\
\hline Sex $\times$ Suppress & & & & & & & -.06 & \\
\hline Sex $\times$ Sreappraisal & & & & & & & .06 & \\
\hline
\end{tabular}

Note: Gender code $0=$ male $/ 1=$ female; ${ }^{*} p<.05 .{ }^{*} p<0.1$.

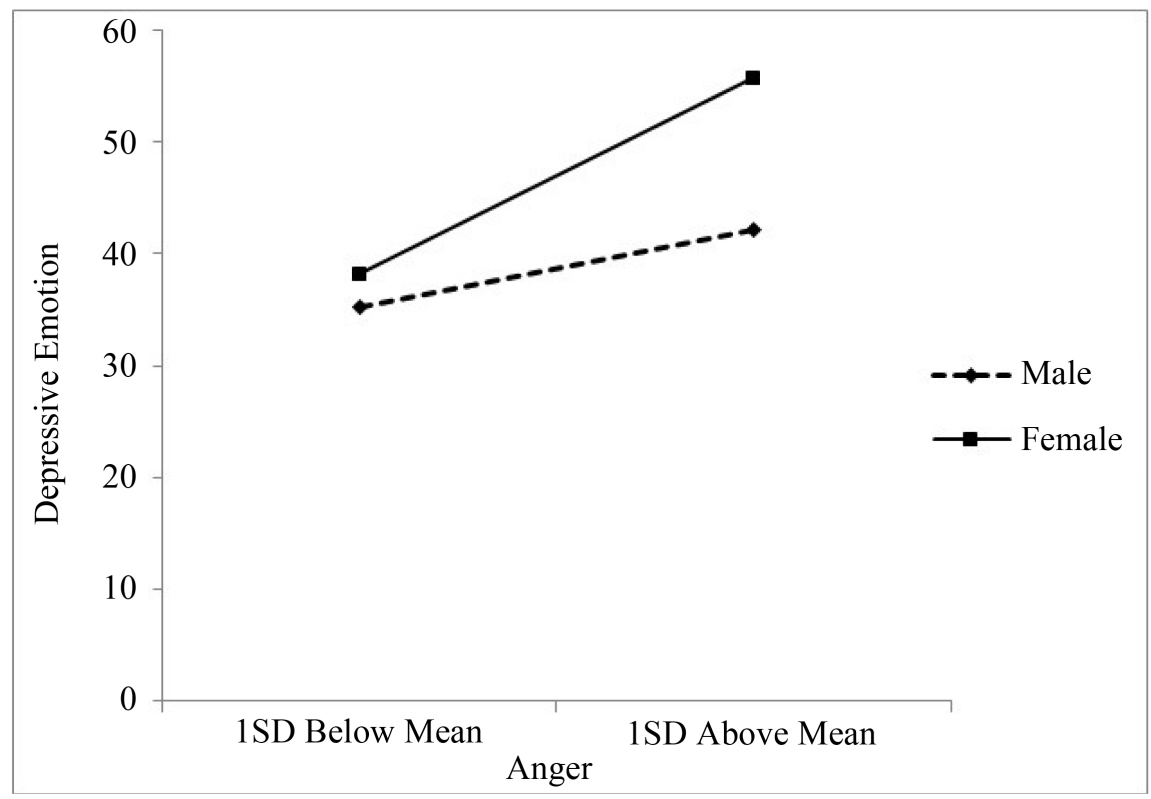

Figure 1. Examining the gender $\times$ anger (1 SD above the mean) and low (1 SD below the mean) anger interaction. 
males (beta $=.21, p>.10$ ), the relationship between own anger and depression was significantly positive for females (beta $=.49, p<.01$ ). Moreover, as can be seen in Figure 1 , females high in own anger $(\mathrm{m}=55.71)$ showed higher depression than did the male group $(\mathrm{m}=35.18)$ (beta $=.36, p<.05)$. The levels of depression did not differ between the male $(\mathrm{m}=35.18)$ and female groups (38.21) which were low in own anger (beta $=.11$, $p>.05)$. These results indicate that for females only, high levels of anger increased a risk for depression.

\section{Discussion and Conclusion}

Hypothesis 1 was supported. Russians, who are assumed to be collectivistic, more frequently used suppression as emotion regulation than Japanese did, as we expected. This means that Matsumoto et al. (1998)'s findings obtained by a questionnaire were replicated by the present study using a role-playing method.

Hypothesis 2 was not supported; instead, suppression of anger decreased depression among Russians. There seem to be two possible interpretations. One is that a decrease of depression might have been caused by a chronic use of suppression of anger among Russians. Butler, Lee and Gross (2007) demonstrated that the effects of suppression of emotion suppression are affected by a culture. For Americans holding Western-European values, habitual suppression was associated with self-protective goals and negative emotion. These deleterious effects were reduced when individuals with more Asian values suppressed emotion. Thus these reductions were mediated by cultural differences in the responsiveness to the suppressors. Matsumoto et al. (1998) found that Russians as collectivists have a strong tendency to suppress expressions of any emotions in social situations. If they are accustomed to suppress anger and have values in which people are open to suppress anger, they may become less frustrated and less depressed with the suppression of anger and, instead, they may be able to alleviate negative emotions including anger and depression by suppression.

The other interpretation is that the unexpected finding is related to different levels of suppression. If one refrains from behavioral expressions of anger, it causes a stress and so generates frustration or depression. If suppression occurs at a cognitive level, not at a behavioral one, however, it may lead to a different consequence. Research found that depressive persons have a cognitive tendency, that is, a rumination of stressful experiences (Alloy et al., 2000). If suppression of negative emotions interferes with the rumination, it may decrease depression. The present results might suggest that Russians use suppression of anger at cognitive level.

Both Hypothesis 3 predicting that Japanese would more frequently use reappraisal than Russians and Hypothesis 4 that reappraisal would increase depression among Japanese but not among Russians were supported. These findings suggest that Japanese frequently attempt a reappraisal of the situation evoking anger but it was sometimes frustrating for Japanese. It seems that they want to avoid directly facing antagonistic emotions such as anger or hostile because these emotions make them recognize that they are involved in a negative relationship with others. They might fear the recogni- 
tion that some other person is harming them or has a malicious intent against them, so they might attempt to deny the recognition by reappraising the situations. Since reappraisal of the situation is urged by social anxiety, however, it may be accompanied by frustrating emotions, that is, depression.

We did not make any specific prediction on the relationships between distraction and depression, but there was a negative relationship between them both in Japanese and Russian samples. It seems curious that the transcultural finding is not consistent with a typical view in health psychology that distraction is a constructive strategy to reduce negative emotions (De Castro, Veerman, Koops, Bosch, \& Monshouwer, 2002; De Castro, Merk, Koops, Veerman, \& Bosch, 2005). In the present study, we measured distraction by two items, "talk it with someone" and "do something fun"; results suggest that distraction by these behaviors or to think doing these behaviors, at least, was not effective to reduce negative emotions, but rather just transformed a kind of negative emotion (anger) into another kind of negative emotion (depression). Other type of distraction, for example, physical exercise, might be effective in a way that health psychologists expect. Or, distraction might not substantially have such an alleviating effect for anger. Future research must deal with the important issue by measuring a wide range of distraction behaviors.

The hypothesis 5 was supported. Females used more emotion regulation and felt more depression than males in both samples. The results were consistent with previous findings. The present finding suggests that females' tendency of being depressive is caused by their propensity of inhibiting anger in socially provocative situations. The results which indicated that for Japanese females only, high levels of anger increased a risk for depression, suggested that their propensity was also affected by cultural differences. Further researches are needed.

\section{Limitation}

The present findings were obtained by self-reported measures of cognitive and emotional variables in hypothetical-social provocative situations, so they are not strong in predicting actual cognitions and emotions in real-life provocative situations (e.g., Dodge, Pettit, McClaskey, Brown, \& Gottman, 1986). Therefore, these must be replicated by using different research methods.

We conducted cross-cultural studies about relationship between emotion regulation and depression in Japan and Russia, and found some common characteristics and differences of in both countries. For the future, the findings must be confirmed in more than two countries which have different cultural backgrounds other than both countries.

\section{Conflict of Interest}

The authors confirm that this article content has no conflict of interest.

\section{References}

Aiken, L. S., West, S. G., \& Reno, R. R. (1991). Multiple Regression: Testing and Interpreting In- 
teractions. New York: Sage.

Aizawa, N. (2011). A Preliminary Study on the Construction of Intent-Ambiguous Provoking Situations and Estranging Situations. Bulletin of the Graduate School of Human Development and Environment Kobe University, 4, 107-122. (In Japanese)

Alloy, L. B., Abramson, L. Y., Hogan, M. E., Whitehouse, W. G., Rose, D. T., Robinson, M. S., Kim, R. S., \& Lapkin, J. B. (2000). The Temple-Wisconsin Cognitive Vulnerability to Depression Project: Lifetime History of Axis I Psychopathology in Individuals at High and Low Cognitive Risk for Depression. Journal of Abnormal Psychology, 109, 403.

http://dx.doi.org/10.1037/0021-843X.109.3.403

Bridewell, W. B., \& Chang, E. C. (1997). Distinguishing between Anxiety, Depression, and Hostility: Relations to Anger-In, Anger-Out, and Anger Control. Personality and Individual Differences, 22, 587-590. http://dx.doi.org/10.1016/S0191-8869(96)00224-3

Brummett, B. H., Babyak, M. A., Barefoot, J. C., Bosworth, H. B., Clapp-Channing, N. E., Siegler, I. C., Williams Jr., R. B., \& Mark, D. B. (1998). Social Support and Hostility as Predictors of Depressive Symptoms in Cardiac Patients One Month after Hospitalization: A Prospective Study. Psychosomatic Medicine, 60, 707-713.

http://dx.doi.org/10.1097/00006842-199811000-00008

Butler, E. A., Lee, T. L., \& Gross, J. J. (2007). Emotion Regulation and Culture: Are the Social Consequences of Emotion Suppression Culture-Specific? Emotion, 7, 30. http://dx.doi.org/10.1037/1528-3542.7.1.30

Crick, N. R., \& Dodge, K. A. (1996). Social Information-Processing Mechanisms in Reactive and Proactive Aggression. Child Development, 67, 993-1002. http://dx.doi.org/10.2307/1131875

Crick, N. R., \& Grotpeter, J. K. (1995). Relational Aggression, Gender, and Social-Psychological Adjustment. Child Development, 66, 710-722. http://dx.doi.org/10.2307/1131945

Culbertson, F. M. (1997). Depression and Gender: An International Review. American Psychologist, 52, 25. http://dx.doi.org/10.1037/0003-066X.52.1.25

De Castro, B. O., Merk, W., Koops, W., Veerman, J. W., \& Bosch, J. D. (2005). Emotions in Social Information Processing and Their Relations with Reactive and Proactive Aggression in Referred Aggressive Boys. Journal of Clinical Child and Adolescent Psychology, 34, 105-116. http://dx.doi.org/10.1207/s15374424jccp3401_10

De Castro, B. O., Veerman, J. W., Koops, W., Bosch, J. D., \& Monshouwer, H. J. (2002). Hostile Attribution of Intent and Aggressive Behavior: A Meta-Analysis. Child Development, 73, 916934.

Dodge, K. A., \& Coie, J. D. (1987). Social-Information-Processing Factors in Reactive and Proactive Aggression in Children's Peer Groups. Journal of Personality and Social Psychology, 53, 1146. http://dx.doi.org/10.1037/0022-3514.53.6.1146

Dodge, K. A., Pettit, G. S., McClaskey, C. L., Brown, M. M., \& Gottman, J. M. (1986). Social Competence in Children. Monographs of the Society for Research in Child Development, 51, 1-85. http://dx.doi.org/10.2307/1165906

Field, T. (1994). The Effects of Mother's Physical and Emotional Unavailability on Emotion Regulation. Monographs of the Society for Research in Child Development, 59, 208-227. http://dx.doi.org/10.2307/1166147

Garnefski, N., Teerds, J., Kraaij, V., Legerstee, J., \& van den Kommer, T. (2004). Cognitive Emotion Regulation Strategies and Depressive Symptoms: Differences between Males and Females. Personality and Individual Differences, 36, 267-276. http://dx.doi.org/10.1016/S0191-8869(03)00083-7

Gross, J. J., \& John, O. P. (2003). Individual Differences in Two Emotion Regulation Processes: 
Implications for Affect, Relationships, and Well-Being. Journal of Personality and Social Psychology, 85, 348. http://dx.doi.org/10.1037/0022-3514.85.2.348

Kawabata, T., \& Ohbuchi, K. (2014). The Relation on Inexpressive Aggression and Depression in College Students-From the Standpoint of the Social Information-Processing Model. Bulletin of Shokei Gakuin University, 68, 91-101. (In Japanese)

Matsumoto, D., LeRoux, J. A., Bernhard, R., \& Gray, H. (2004). Unraveling the Psychological Correlates of Intercultural Adjustment Potential. International Journal of Intercultural Relations, 28, 281-309. http://dx.doi.org/10.1016/j.ijintrel.2004.06.002

Matsumoto, D., LeRoux, J. A., Iwamoto, M., Choi, J. W., Rogers, D., Tatani, H., \& Uchida, H. (2003). The Robustness of the Intercultural Adjustment Potential Scale (ICAPS): The Search for a Universal Psychological Engine of Adjustment. International Journal of Intercultural Relations, 27, 543-562. http://dx.doi.org/10.1016/S0147-1767(03)00053-1

Matsumoto, D., LeRoux, J., Ratzlaff, C., Tatani, H., Uchida, H., Kim, C., \& Araki, S. (2001). Development and Validation of a Measure of Intercultural Adjustment Potential in Japanese Sojourners: The Intercultural Adjustment Potential Scale (ICAPS). International Journal of Intercultural Relations, 25, 483-510. http://dx.doi.org/10.1016/S0147-1767(01)00019-0

Matsumoto, D., Takeuchi, S., Andayani, S., Kouznetsova, N., \& Krupp, D. (1998). The Contribution of Individualism vs. Collectivism to Cross-National Differences in Display Rules. Asian Journal of Social Psychology, 1, 147-165. http://dx.doi.org/10.1111/1467-839X.00010

Matsumoto, D., Yoo, S. H., \& Nakagawa, S. (2008). Culture, Emotion Regulation, and Adjustment. Journal of Personality and Social Psychology, 94, 925-937. http://dx.doi.org/10.1037/0022-3514.94.6.925

Triandis, H. C., Bontempo, R., Villareal, M. J., Asai, M., \& Lucca, N. (1988). Individualism and Collectivism: Cross-Cultural Perspectives on Self-Ingroup Relationships. Journal of personality and Social Psychology, 54, 323-338. http://dx.doi.org/10.1037/0022-3514.54.2.323

Weissman, M. M., Bland, R. C., Canino, G. J., Faravelli, C., Greenwald, S., Hwu, H. G. et al. (1996). Cross-National Epidemiology of Major Depression and Bipolar Disorder. JAMA, 276, 293-299. http://dx.doi.org/10.1001/jama.1996.03540040037030

World Health Organization (2006). Preventing Suicide: A Resource at Work.

World Health Organization (2012). Public Health Action for the Prevention of Suicide: A Framework.

Yamasaki, K., \& Nishida, N. (2009). The Relationship between Three Types of Aggression and Peer Relations in Elementary School Children. International Journal of Psychology, 44, 179186. http://dx.doi.org/10.1080/00207590701656770 
Submit or recommend next manuscript to SCIRP and we will provide best service for you:

Accepting pre-submission inquiries through Email, Facebook, LinkedIn, Twitter, etc. A wide selection of journals (inclusive of 9 subjects, more than 200 journals)

Providing 24-hour high-quality service

User-friendly online submission system

Fair and swift peer-review system

Efficient typesetting and proofreading procedure

Display of the result of downloads and visits, as well as the number of cited articles

Maximum dissemination of your research work

Submit your manuscript at: http://papersubmission.scirp.org/

Or contact psych@scirp.org 